in the aetiology of thrombosis. Experimental evidence casts doubt on the possibility that stasis alone produces massive venous thrombosis, for blood usually remains fluid in vessels with a normal endothelial lining when they are isolated from the general circulation. Conversely, the formation of a thrombus in static blood is observed in the presence of active intermediates of coagulation, ${ }^{3}$ whether they are produced locally in response to an alteration of the endothelium or at a remote site before they are cleared from the blood.

Laboratory tests for the coagulation intermediates in the blood, and hence of a potentially "hypercoagulable" state," are imperfect. It has long been suspected that activation may occur in a small part of the circulation and yet produce little evidence of its existence in conventional tests applied to blood collected from an antecubital vein. The studies reported by Dr. John Bonnar and his colleagues in the B.M.F. this week at page 564 are important in offering a direct comparison of platelet, coagulation, and fibrinolytic measurements in blood collected simultaneously from the uterine vein and from a peripheral vein during caesarean section. Qualitatively similar but quantitatively much greater changes were found in the blood from the uterine vein. This confirms the interpretation of the remote changes as evidence for the stimulation of coagulation and fibrinolysis locally in the uterus and throws light on the clearance mechanism at work.

The early shortening of the clotting time, kaolincephalin time, and partial thromboplastin time is related to the appearance of increased factor VIII levels in the plasma, perhaps due to the activation of this factor by traces of thrombin. ${ }^{5}$ This is followed by a fall in the concentration of platelets, coagulation, and fibrinolytic factors, as they are consumed more rapidly than they can be replaced. In each case pronounced changes in uterine blood are almost obscured in peripheral blood. Later, a rise is observed in the concentration of those factors which had fallen; the increased utilization could perhaps have stimulated an increased production of the factors.

The study underlines the significance to be attached to raised levels of factor VIII in one-stage assays on peripheral blood as evidence for the existence of the local stimulation of coagulation somewhere in the body. ${ }^{6}$ Evidence is presented to show there is simultaneous activation of coagulation and fibrinolysis within the uterus. Greater concentrations of the fibrin-degradation products of fibrinolysis in the uterine vein than in the arterial circulation have been observed previously at caesarean section. ${ }^{7}$ The two enzyme systems responsible for the presence of fibrin in the body are closely related and appear to be activated by similar stimuli. ${ }^{8}$ The steady accumulation of fibrin degradation products up to 10 to 14 days suggests that the stimulus to coagulation continues for relatively long periods. If active intermediates continue to circulate, they could contribute to the incidence of thrombosis in the puerperium.

These observations do not diminish the importance of

1 Spaet, T. H., Thrombosis et Diathesis Haemorrhagica, 1962, 8, 276.

2 Wessler, S., Yin, E. T., Gaston, L. W., and Nicol, I., Thrombosis et Diathesis Haemorrhagica, 1967, 18, 12.

3 Wessler, S., Reiner, L., Freiman, D. G., Reimer, S. M., and Lertzman, M., Circulation, 1959, 20, 864.

- Duckert, F., and Streuli, F., 1966, Thrombosis et Diathesis Haemorrhagica, 1966, Suppl. 21, 185.

Rapaport, S. I., Schiffman, S., Patch, M. J., and Ames, S. B., Blood, 1963, 21, 221 .

6 Penick, G. D., Roberts, H. R., and Dejanov, I. I., Federation Proceedings, $1965,24,835$.

Basu, H. K., Fournal of Obstetrics and Gynaecology of the British Commonwealth, 1969, 76, 481 'Ogston, D., Ogston, C. M., Ratnoff, O. D., and Forbes, C. D., fournal of

s Scott, J. S., British Medical Bulletin, 1968, 24, 32. myometrial contraction in the arrest of bleeding after childbirth, but they show there is an additional need for normal platelet function and fibrin formation. Complications of pregnancy which intensify the stimulus to coagulation and fibrinolysis may lead to very low blood levels of platelets and coagulation factors, with an excessive accumulation of the products of fibrinolysis, all tending to cause a failure of haemostasis. ${ }^{9}$ Nevertheless, bleeding is not inevitable unless both uterine contraction and blood coagulation fail together.

\section{Safety of Food Additives}

The health hazards that may be associated with the use of substances added to food are constantly reiterated. The latest report of the Food Additives and Contaminants Committee ${ }^{1}$ contains decisions and recommendations on the safety of 98 substances which have been used, or proposed for use, as emulsifiers and stabilizers in our food. These substances are intended to maintain a uniform dispersion of two immiscible substances, and some are used in basic articles of diet such as bread, margarine, and chocolate. Others are needed in the preparation of "convenience" foods. These are complex, premixed foods designed to save time for working wives.

The large number of compounds included in the present list is accounted for by the committee's honesty in discarding the seven groups of substances which together with three individual compounds were considered in earlier reports. Instead they rightly identify the individual compounds. They next recommend that specifications for chemical identity and purity be demanded for all substances proposed for addition to our food. To simplify the problems the report proposes that a number of substances be "defined out" because of their close resemblance to food constituents. Proteins and malt extracts are thus excluded, but various starch derivatives get less generous treatment.

Another principle which emerges is that certain staple articles of diet such as bread and potatoes are protected in that some emulsifiers must not be added to them, while milk and flour itself must be kept free of all added emulsifiers. In the ever more affluent society bread and potatoes may soon cease to be staple articles. On the other hand, if the young are to be considered as particularly sensitive targets for potentially injurious substances, then additives to chocolate and sweets should surely require special scrutiny. However, though chocolate may be considered a natural food, it is doubtful whether any proposed additive with the characteristics of theobromine, present in cocoa beans, would ever be accepted as an additive to boiled sweets. The pharmacological characteristics of the natural ingredients of our food are not presumably the concern of a committee on additives and contaminants.

It is easy enough for the reader to be critical of some of the apparently fine distinctions drawn between the biological effects of some of the materials considered in this report. Why should the sucrose esters of fatty acids be rejected while dioctyl sodium sulphosuccinate is accepted? What is perhaps more surprising is the acceptance without comment of carrageen on the basis that it has been used in food and pharmaceutical preparations for many years. Recent experi-

\footnotetext{
1 Ministry of Agriculture, Fisheries and Food, Food Additives and Contaminants Committee, Report on the Review of the Emulsifiers and Stabiliztrs in Food Regulations, 1962. London, H.M.S.O. Office, 1970. 2 Marcus, R., and Watt, J., Lancet, 1969, 2, 489.
} 
mental evidence shows that in the diet of certain animals it can lead to ulceration of the intestinal tract. ${ }^{2}$

From a cursory study of the chemical constitution of most of the additives it seems unlikely that many of them would be toxic, and unusual compounds like brominated vegetable oils have already been rejected, apparently on the basis of evidence obtained in both Canada and the U.K. What is not made clear is whether the halogenated vegetable oils accumulate totally in human body fat or whether the level, like that of the halogenated hydrocarbons (D.D.T.), reflects the daily intake.

The medical profession should be grateful that so many distinguished scientists with many other commitments are prepared to devote their time and exercise their judgement on the safety or otherwise of hundreds of food additives. The existing system in this country allows the executive to make decisions based on the advice of disinterested experts, and fortunately it does not have to rely on official experts.

It is difficult to know how long the present system can continue, but it is important to recognize that most of the decisions reached are based on an expert's interpretation of the significance of animal experiments in relation to the possible risks to man. No action on food additives has had to be taken on the basis of direct evidence of harm to man. If food, including its additives, has an effect on people's health, the first clues will come from doctors who note unusual associations. Just as a doctor should ask his patients their occupation, so may a simple inquiry about dietary habits disclose something injurious to health.

\section{More Polluted Air}

The struggle for clean urban air is once again in the doldrums, and unless something is done soon to safeguard the clean-air policy hard-won progress will be lost. Last winter there were serious shortages of smokeless solid fuels. Both domestic users and institutions such as schools lacked them. The undertaking given in a White Paper $^{1}$ last week to see that more fuel for smokeless burning will be available next winter is therefore welcome. The recently published report of the Royal College of Physicians of London ${ }^{2}$ should also stimulate fresh interest in this important problem of environmental health.

The general supply of solid smokeless fuels is the responsibility of the Ministry of Technology, which has a concern for the viability of the coal industry, while the clean air policy is the responsibility of the Ministry of Housing and Local Government. But it seems that where shortages of smokeless fuels arise the Ministry of Housing and Local Government is prepared to suspend smoke control orders to avoid unnecessary hardship. While this may have to be done if people are to keep warm, surely these shortages are a wholly unnecessary threat to health. It is to be hoped that any such temporary suspension would be given only in circumstances of real difficulty, and it should be the subject of close and continuing scrutiny. Otherwise urban pollution of the air will once again start to increase, with all its adverse effects on community

\footnotetext{
1 The Protection of the Environment: The Fight Against Pollution, Cmnd. 4373. London, H.M.S.O., 1970.

2 Committee of the Royal College of Physicians of London, Air Pollution and Health. London, Pitman, 1970.

${ }^{3}$ British Medical fournal, 1970, 2, 190.

- Mortality and Morbidity during the London Fog of December 1952, Report on Public Health and Medical Subjects, No. 95. London, H.M.S.O., 1953.

5 British Medical fournal, 1963, 1, 489.

- Brazell, J. H., Nature, 1970, 226, 694.
}

health. ${ }^{23}$ If solid smokeless fuels are to continue in short supply, alternative fuels must be considered as a matter of urgency. There is little point in local authorities accepting solid-fuel burning appliances in smoke-control areas unless a plentiful supply of fuel at a reasonable price is available. Price is important, not least for the elderly, who tend to adhere to open fires to which they have been used and are less keen to change to one of the cleaner forms of house warming.

The benefits to health of smokeless zones must be regarded as great and undoubted, and no excuse should be accepted to allow central or local government to slow the advance towards a less polluted urban atmosphere. As smoke control costs money, some local authorities are only too keen to find a reason for doing nothing about it; they require prodding, which is the duty of central Government. Unless vigorous action is taken soon we shall see the sort of recurrence of the ill-effects of polluted air on the respiratory tract of which the London smogs have provided classic examples, the one in 1952 causing 4,000 deaths. ${ }^{4}$ And reduction of smoke in the atmosphere allows us to enjoy more of that precious commodity, sunshine. ${ }^{6}$

\section{Lung Biopsy}

Some 20 years ago lung biopsy rapidly found favour as a diagnostic procedure. Among the reasons for this were the comparative ease with which tissue could be obtained, a mounting interest in diffuse infiltrations of the lungs, about which little was known at that time, and the comforting thought that should tuberculosis be encountered the newly discovered antituberculosis drugs would probably prevent dissemination of the infection.

In its simplest form biopsy consists of no more than the aspiration of a small core of tissue into a wide-bore needle. Failure to secure a satisfactory specimen is fairly common, and even when the aspiration is successful the fragment is often too small to yield a firm pathological diagnosis, especially in diffuse disease of the lung. Latterly, with a view to aspirating adequate material with greater consistency, biopsy has been performed by inserting a rapidly rotating drill, sometimes an alarming undertaking for both patient and operator. Any form of needling is liable to be followed by a troublesome pneumothorax or pleural infection, and owing to the indifferent contribution it has made in assisting diagnosis over the years the method has now been virtually abandoned. A notable exception is the occasional patient who is unsuitable for thoracotomy and who has a peripheral mass, usually carcinomatous, the nature of which cannot be determined by other means. For patients who are suitable for surgical treatment and who present with radiographic evidence of localized lung disease of uncertain aetiology thoracotomy is ordinarily indicated, both for diagnosis and as a preliminary to treatment by resection.

Diffuse disease of the lungs may have many different causes, some of which have similar morbid anatomical appearances. Hence a much larger fragment of lung must be obtained at biopsy than could possibly be aspirated through a needle. For this purpose an open or surgical lung biopsy is necessary and is carried out through a limited thoracotomy with subperiostial rib resection. The site of election is laterally in the line of the greater fissure or, on the right side, the middle lobe, where an edge of tissue is available. In the B.M.F. this week (page 57) Professor J. G. Scadding relates his experience of open lung biopsy during the past 13 years, in which he has called it into use on only 43 occasions. The diagnoses reached 